\title{
PEMAHAMAN MAHASISWA DAN KARYAWAN TERHADAP ADIPURA
}

\author{
Hadinoto, Eni Suhesti \\ Staf Pengajar Fakultas Kehutanan Universitas Lancang Kuning \\ Jln. Yos Sudarso Km. 8 Rumbai Pekanbaru Riau \\ Email : hdinto@yahoo.co.id \& hesti1170@yahoo.co.id \\ Telp./Fax. (0761) 54092
}

\begin{abstract}
One of the government's efforts in maintaining the ecological balance in urban areas is to give an award in the form of "ADIPURA" to the cities judged to meet criteria such as; hygiene, beauty, beauty, comfort, green and other environmental aspects. The purpose of research is to identify the level of understanding of students and employees of the University Lancang Kuning Pekanbaru. Primary data was collected through interviews with respondents using the help of questionnaires (attached). Determination of the respondents were randomized (random sampling) for each faculty (S1). The number of respondents who were taken as many as 30 students and 30 employees. Data obtained from filling the questionnaire will be processed in the following manner; the number of questions in questionnaires of 20 questions. Each question provided three answers for respondents to choose according to their understanding. To quantify the data by using a Likert scale, which is any of respondents who are knowledgeable about Verse (answer "Yes") rated 3, which is not yet fully understood (answered "Doubt") was given a value of 2 and that does not understand (answered "No") by a value of 1. the data obtained will be analyzed descriptively, the depiction of data obtained as it is, without any lawyergeneralisasian. Data will be illustrated through tables or graphs. Based on the research results can be summarized as follows: (1) the level of student understanding of the Lancang Kuning University adipura for high category (33.33\%), moderate (56.67\%) and low (10\%); (2) the level of employees' understanding of the Lancang Kuning University adipura for high category (63.33\%) and moderate (36.67\%).
\end{abstract}

Keywords: adipura, comprehension, students, employees

\section{PENDAHULUAN}

\section{Latar Belakang}

Pesatnya perkembangan dan pemekaran wilayah perkotaan telah merubah lansekap kota. Banyak ruang terbuka hijau yang telah dijadikan sarana dan prasarana publik, yang berdampak pada perubahan penutupan dan penggunaan lahan. Perkembangan kota akibat pembangunan infrastruktur yang berupa pembangunan fisik 
seharusnya tetap memperhatikan keseimbangan ekosistem dan kualitas lingkungan yang baik.

Semakin tidak harmonisnya hubungan manusia dengan alam mengakibatkan keadaan lingkungan di perkotaan maju secara ekonomi tetapi mengalami kemunduran secara ekologi. Padahal kestabilan ekologi di perkotaan sangat penting, sama pentingnya dengan kestabilan ekonomi. Oleh karena terganggunya kestabilan ekologi perkotaan, maka timbul beberapa permasalahan alam antara lain : suhu udara perkotaan meningkat, penurunan air tanah, banjir/genangan, penurunan permukaan tanah, intrusi air laut, abrasi pantai, pencemaran air, pencemaran udara seperti meningkatnya kadar $\mathrm{CO}$, rusaknya ozon, banyak debu, suasana yang gersang, monoton, bising dan kotor.

Salah satu upaya pemerintah dalam rangka menjaga keseimbangan ekologi di wilayah perkotaan adalah dengan memberikan penghargaan berupa "ADIPURA" kepada kota-kota yang dinilai memenuhi kriteria seperti ; aspek kebersihan, keindahan, keasrian, kenyamanan, hijau dan aspek lingkungan lainnya. Dengan demikian diharapkan kota-kota besar dapat melakukan kegiatan seperti tersebut di atas. Penghargaan ini sudah dimulai sejak tahun 1970-an sampai sekarang. Sebagian kota-kota di Indonesia telah mendapatkan penghargaan tersebut, bahkan ada beberapa kota yang mendapatkannya lebih dari satu kali.

Adipura adalah adalah sebuah penghargaan bagi kota di Indonesia yang berhasil dalam kebersihan serta pengelolaan lingkungan perkotaan. Adipura pada awalnya diselenggarakan oleh Kementerian Negara Lingkungan Hidup. Selain dari penglolaan yang baik oleh pemerintah, kesadaran dan pemahaman masyarakat sendiri akan lingkungan haruslah berkembangan. Sehingga akan terjalin dan tercipta lingkungan yang bersih dan indah. Pekanbaru sendiri juga telah 8 kali mendapat penghargaan "Adipura" untuk kategori kota besar. Meskipun demikian belum semua masyarakat termasuk di dalamnya mahasiswa dan karyawan Universitas Lancang Kuning Pekanbaru, mengetahui tentang penghargaan "Adipura" itu sendiri. Oleh karena itu kajian untuk mengidentifikasi tingkat pemahaman tentang Adipura bagi mahasiswa dan karyawan perlu dilakukan.

\section{Urgensi Penelitian}


Penyediaan ruang terbuka hijau perkotaan dimaksudkan untuk mengoptimalkan kondisi lingkungan yang ada di daerah perkotaan menjadi lebih baik. Saat ini selain dari berkurangnya Ruang Terbuka Hijau perkotaan juga adanya berbagai pencemaran lingkungan. Salah satu penyebab pencemaran adalah sampah. Masalah sampah ini sering terjadi di daerah perkotaan, apabila tidak dikelola dengan baik maka akan menimbulkan bencana antara lain banjir. Hijaunya kota tidak hanya menjadikan kota itu indah dan sejuk namun aspek kelestarian, keserasian, keselarasan dan keseimbangan sumberdaya alam, yang selanjutnya akan memberikan jasa-jasa berupa kenyamanan, kesegaran, kota bebas polusi, bebas kebisingan dan lainnya.

Kota perlu dikembangkan untuk memenuhi tuntutannya yang terus meningkat. Pada saat menentukan arah kebijakan pengembangannya perlu dibuatkan pola perencanaan pengembangan berdasarkan data yang ada dan kebutuhan yang harus dipenuhi kota tersebut. Kota dengan perencanaan yang kurang memadai akan menjadi kota yang lesu, sakit dan semrawut yang jika tidak dilakukan usaha penataan kembali, akan menjadi kota mati. Kota-kota seperti itu layak diberi julukan miserapolis (ghetto) yang berarti kota yang sakit, menyedihkan, melarat, kotor dan acak-acakan.

Kesadaran pemerintah akan perlunya pengelolaan lingkungan di perkotaan sesungguhnya sudah sejak lama. Namun pada waktu itu gerakan tersebut masih belum menyeluruh diterima oleh seluruh warga masyarakat dan belum semua kota benar-benar mengusahakannya secara sungguhsungguh.

\section{Tujuan Penelitian}

Penelitian ini bertujuan untuk :

Mengidentifikasi tingkat pemahaman mahasiswa dan karyawan Universitas Lancang Kuning Pekanbaru terhadap "adipura".

\section{Manfaat Penelitian}

Hasil penelitian ini diharapkan merupakan data awal dalam penyadaran terhadap masyarakat tentang pentingnya menjaga lingkungan perkotaan

\section{METODE PENELITIAN}

Lokasi penelitian di kampus Universitas Lancang Kuning Pekanbaru

\section{Pengumpulan data}


Data yang dikumpulkan dalam penelitian ini adalah data primer dan data sekunder :

\section{a. Pengumpulan Data Sekunder}

Pengumpulan data dilakukan dengan penelusuran pustaka atau data yang ada di lembaga/institusi terkait. Data sekunder dikumpulkan dari berbagai sumber yang relevan dalam rentang waktu tertentu.

\section{b. Pengumpulan Data Primer}

Data primer diperoleh melalui kegiatan survey dan observasi terhadap objek penelitian. Data yang diambil berupa pemahaman mahasiswa dan karyawan Universitas Lancang Kuning

\section{Pekanbaru}

\section{Metode Pengumpulan}

Data primer dikumpulkan melalui wawancara dengan responden menggunakan bantuan quisioner (terlampir). Penentuan responden dilakukan secara acak (random sampling) untuk setiap fakultas (S1). Jumlah responden yang diambil sebanyak 30 orang mahasiswa (minimal 3 orang setiap fakultas) dan 30 orang karyawan Universitas Lancang Kuning..
Data yang diperoleh dari hasil pengisian kuisioner akan diolah dengan cara sebagai berikut

Tingkat Pemahaman

secara

\section{Keseluruhan}

Jumlah soal dalam quisioner sebanyak 20 soal. Masing-masing pertanyaan disediakan tiga jawaban bagi responden untuk memilih sesuai dengan pemahaman yang mereka miliki. Untuk mengkuantifikasikan data dengan menggunakan skala Likert, yaitu setiap jawaban responden yang memahami tentang Adipura (menjawab "Ya") diberi nilai 3, yang belum sepenuhnya memahami (menjawab "Ragu") diberi nilai 2 dan yang tidak memahami (menjawab "Tidak") diberi nilai 1.

Berdasarkan pemberian nilai bagi setiap jawaban masing-masing responden memiliki peluang memperoleh skor jawaban untuk pemahaman terhadap Adipura minimal 20 (memilih semua jawaban dengan nilai 1 atau semua pilih jawaban "tidak") dan maksimal jawaban 60 (memilih semua jawaban dengan nilai 3 atau semua pilih jawaban "Ya")

Untuk menentukan tingkat pemahaman masyarakat terhadap Adipura dibuat kisaran skor yaitu :

\section{Analisis Data}


a. Tingkat pemahaman masyarakat terhadap Adipura rendah, skor jawaban : $20-33$

b. Tingkat pemahaman masyarakat terhadap Adipura sedang, skor jawaban : $34-47$

c. Tingkat pemahaman masyarakat terhadap Adipura tinggi, skor jawaban : $48-60$

\section{Tingkat Pemahaman setiap Bagian}

\section{Pengertian}

Jumlah soal dalam quisioner sebanyak 6 soal.

Berdasarkan pemberian nilai bagi setiap jawaban masing-masing responden memiliki peluang memperoleh skor jawaban untuk pemahaman terhadap Adipura minimal 6 (memilih semua jawaban dengan nilai 1 atau semua pilih jawaban "tidak") dan maksimal jawaban 18 (memilih semua jawaban dengan nilai 3 atau semua pilih jawaban "Ya")

Untuk menentukan tingkat pemahaman masyarakat terhadap Adipura dibuat kisaran skor yaitu :

a. Tingkat pemahaman masyarakat terhadap Adipura rendah, skor jawaban : 6 - 9 b. Tingkat pemahaman masyarakat terhadap Adipura sedang, skor jawaban : $10-14$

c. Tingkat pemahaman masyarakat terhadap Adipura tinggi, skor jawaban : $15-18$

\section{Tanggapan}

Cara perhitungan sama dengan point 1 (Pengertian)

\section{Pengaruh}

Jumlah soal dalam quisioner sebanyak 4 soal. Berdasarkan pemberian nilai bagi setiap jawaban masing-masing responden memiliki peluang memperoleh skor jawaban untuk pemahaman terhadap Adipura minimal 4 (memilih semua jawaban dengan nilai 1 atau semua pilih jawaban "tidak") dan maksimal jawaban 12 (memilih semua jawaban dengan nilai 3 atau semua pilih jawaban "Ya")

Untuk menentukan tingkat pemahaman masyarakat terhadap Adipura dibuat kisaran skor yaitu :

a. Tingkat pemahaman masyarakat terhadap Adipura rendah, skor jawaban : $4-6$

b. Tingkat pemahaman masyarakat terhadap Adipura sedang, skor jawaban : $7-9$ 
c. Tingkat pemahaman masyarakat terhadap Adipura tinggi, skor jawaban : $10-12$

Data yang diperoleh akan dianalisis secara deskriptif, yaitu penggambaran data yang diperoleh secara apa adanya, tanpa ada penggeneralisasian. Data akan digambarkan melalui tabel atau grafik.

\section{HASIL DAN PEMBAHASAN}

\section{Tingkat Pemahaman Mahasiswa terhadap Adipura}

Tingkat pemahaman mahasiswa terhadap adipura berbeda-beda. Beberapa mahasiswa ada yang memiliki pemahaman yang tinggi tetapi terdapat juga yang pemahamannya sedang dan rendah. Rincian tingkat pemahaman mahasiswa Universitas Lancang Kuning terhadap adipura seperti pada Tabel 1.

Tabel 1. Tingkat pemahaman mahasiswa terhadap adipura

\begin{tabular}{cccc}
\hline No. & Tingkat Pemahaman & $\begin{array}{c}\text { Jumlah } \\
\text { Responden }\end{array}$ & $\%$ \\
\hline 1. & Tinggi & 10 & 33.33 \\
\hline 2. & Sedang & 17 & 56.67 \\
\hline 3. & Rendah & 3 & 10.00 \\
\hline & Jumlah & $\mathbf{3 0}$ & $\mathbf{1 0 0}$ \\
\hline
\end{tabular}

Berdasar pada Tabel 1 di atas terlihat bahwa sebagian besar $(56,67 \%)$ mahasiswa memiliki tingkat pemahaman terhadap adipura dalam kategori sedang. Hal tersebut diduga mahasiswa belum cukup memiliki pengetahuan tentang hal yang tidak langsung berhubungan dengan materi perkuliahan. Mahasiswa masih fokus kepada materi kuliah, tugas dan praktikum, sehingga hanya sebagian mahasiswa yang memiliki tingkat pengetahuan yang tinggi dan sedikit yang tidak memahami.

Tingkat Pemahaman Mahasiswa terhadap Adipura Berdasar pada Pengertian

Tingkat pemahaman mahasiswa terhadap adipura berdasar pada pengertian adipura berbeda-beda. Secara umum tingkat pemahaman mahasiswa terhadap pengertian adipura dalam kategori sedang. Rincian tingkat pemahaman mahasiswa Universitas Lancang Kuning terhadap pengertian adipura seperti pada Tabel 2.

Tabel 2. Tingkat pemahaman mahasiswa terhadap adipura berdasar pada "Pengertian Adipura" 


\begin{tabular}{cccc}
\hline No. & Tingkat Pemahaman & $\begin{array}{c}\text { Jumlah } \\
\text { Responden }\end{array}$ & $\%$ \\
\hline 1. & Tinggi & 8 & 26.67 \\
\hline 2. & Sedang & 14 & 46.67 \\
\hline 3. & Rendah & 8 & 26.67 \\
\hline & Jumlah & $\mathbf{3 0}$ & $\mathbf{1 0 0}$ \\
\hline
\end{tabular}

Tingkat Pemahaman Mahasiswa terhadap Adipura Berdasar pada Tanggapan

Tingkat pemahaman mahasiswa terhadap adipura berdasar pada tanggapan adipura berbeda-beda. Secara umum tingkat pemahaman mahasiswa terhadap tanggapan adipura dalam kategori sedang. Rincian tingkat pemahaman mahasiswa Universitas Lancang Kuning terhadap tanggapan adipura seperti pada Tabel 3 .

Tabel 3. Tingkat pemahaman mahasiswa terhadap adipura berdasar pada "Tanggapan Adipura"

\begin{tabular}{cccc}
\hline No. & Tingkat Pemahaman & $\begin{array}{c}\text { Jumlah } \\
\text { Responden }\end{array}$ & $\%$ \\
\hline 1. & Tinggi & 10 & 33.33 \\
\hline 2. & Sedang & 19 & 63.33 \\
\hline 3. & Rendah & 1 & 3.33 \\
\hline & Jumlah & $\mathbf{3 0}$ & $\mathbf{1 0 0}$ \\
\hline
\end{tabular}

Tingkat Pemahaman Mahasiswa terhadap Adipura Berdasar pada Pengaruh

Tingkat pemahaman mahasiswa terhadap adipura berdasar pada pengaruh adipura berbeda-beda. Secara umum tingkat pemahaman mahasiswa terhadap pengaruh adipura dalam kategori sedang. Rincian tingkat pemahaman mahasiswa Universitas Lancang Kuning terhadap pengaruh adipura seperti pada Tabel 4.

Tabel 4. Tingkat pemahaman mahasiswa terhadap adipura berdasar pada "Pengaruh Adipura"

\begin{tabular}{cccc}
\hline No. & Tingkat Pemahaman & $\begin{array}{c}\text { Jumlah } \\
\text { Responden }\end{array}$ & $\%$ \\
\hline 1. & Tinggi & 9 & 30.00 \\
\hline 2. & Sedang & 17 & 56.67 \\
\hline 3. & Rendah & 4 & 13.33 \\
\hline & Jumlah & $\mathbf{3 0}$ & $\mathbf{1 0 0}$ \\
\hline
\end{tabular}


Tingkat Pemahaman Mahasiswa terhadap Adipura Berdasar pada Peran Serta

Tingkat pemahaman mahasiswa terhadap adipura berdasar pada peran serta berbeda-beda. Secara umum tingkat pemahaman mahasiswa

terhadap peran serta dalam kategori tinggi. Rincian tingkat pemahaman mahasiswa Universitas Lancang Kuning terhadap peran serta seperti pada Tabel 5.

Tabel 5. Tingkat pemahaman mahasiswa terhadap adipura berdasar pada "Peran Serta"

\begin{tabular}{cccc}
\hline No. & Tingkat Pemahaman & $\begin{array}{c}\text { Jumlah } \\
\text { Responden }\end{array}$ & $\%$ \\
\hline 1. & Tinggi & 14 & 46.67 \\
\hline 2. & Sedang & 12 & 40.00 \\
\hline 3. & Rendah & 4 & 13.33 \\
\hline & Jumlah & $\mathbf{3 0}$ & $\mathbf{1 0 0}$ \\
\hline
\end{tabular}

Tingkat Pemahaman Karyawan terhadap Adipura

Tingkat pemahaman karyawan terhadap adipura berbeda-beda. Beberapa karyawan ada yang memiliki pemahaman yang tinggi tetapi terdapat juga yang pemahamannya sedang dan rendah. Rincian tingkat pemahaman karyawan Universitas Lancang Kuning terhadap adipura seperti pada Tabel 6.

Tabel 6. Tingkat pemahaman karyawan terhadap adipura

\begin{tabular}{cccc}
\hline No. & Tingkat Pemahaman & $\begin{array}{c}\text { Jumlah } \\
\text { Responden }\end{array}$ & $\%$ \\
\hline 1. & Tinggi & 19 & 63.33 \\
\hline 2. & Sedang & 11 & 36.67 \\
\hline 3. & Rendah & 0 & 0.00 \\
\hline & Jumlah & $\mathbf{3 0}$ & $\mathbf{1 0 0}$ \\
\hline
\end{tabular}

Berdasar pada Tabel 6 di atas terlihat bahwa sebagian besar $(63,33 \%)$ karyawan memiliki tingkat pemahaman terhadap adipura dalam kategori tinggi. Hal tersebut diduga karyawan cukup memiliki pengetahuan tentang hal yang tidak langsung berhubungan dengan tugas pokoknya. Karyawan meskipun fokus pada pekerjaannya tetapi juga mengetahui tentang adipura.

Tingkat Pemahaman Karyawan terhadap Adipura Berdasar pada Pengertian

Tingkat pemahaman karyawan terhadap adipura berdasar pada pengertian adipura berbeda-beda. Secara umum tingkat pemahaman 
karyawan terhadap pengertian adipura dalam kategori tinggi. Rincian tingkat pemahaman karyawan Universitas
Lancang Kuning terhadap pengertian adipura seperti pada Tabel 7 .

Tabel 7. Tingkat pemahaman karyawan terhadap adipura berdasar pada "Pengertian Adipura"

\begin{tabular}{cccc}
\hline No. & Tingkat Pemahaman & $\begin{array}{c}\text { Jumlah } \\
\text { Responden }\end{array}$ & $\%$ \\
\hline 1. & Tinggi & 22 & 73.33 \\
\hline 2. & Sedang & 8 & 26.67 \\
\hline 3. & Rendah & 0 & 0.00 \\
\hline & Jumlah & $\mathbf{3 0}$ & $\mathbf{1 0 0}$ \\
\hline
\end{tabular}

Tingkat Pemahaman Karyawan terhadap Adipura Berdasar pada Tanggapan

Tingkat pemahaman karyawan terhadap adipura berdasar pada tanggapan adipura berbeda-beda. adipura seperti pada Tabel 8. karyawan terhadap tanggapan adipura dalam kategori sedang. Rincian tingkat pemahaman karyawan Universitas Lancang Kuning terhadap tanggapan

Secara umum tingkat pemahaman

Tabel 8. Tingkat pemahaman karyawan terhadap adipura berdasar pada "Tanggapan Adipura"

\begin{tabular}{cccc}
\hline No. & Tingkat Pemahaman & $\begin{array}{c}\text { Jumlah } \\
\text { Responden }\end{array}$ & $\%$ \\
\hline 1. & Tinggi & 8 & 26.67 \\
\hline 2. & Sedang & 22 & 73.33 \\
\hline 3. & Rendah & 0 & 0.00 \\
\hline & Jumlah & $\mathbf{3 0}$ & $\mathbf{1 0 0}$ \\
\hline
\end{tabular}

Tingkat Pemahaman Karyawan karyawan terhadap pengaruh adipura terhadap Adipura Berdasar pada Pengaruh

Tingkat pemahaman karyawan dalam kategori tinggi. Rincian tingkat pemahaman karyawan Universitas terhadap adipura berdasar pada Lancang Kuning terhadap pengaruh pengaruh adipura berbeda-beda. adipura seperti pada Tabel 9. Secara umum tingkat pemahaman 
Tabel 9. Tingkat pemahaman karyawan terhadap adipura berdasar pada "Pengaruh Adipura"

\begin{tabular}{cccc}
\hline No. & Tingkat Pemahaman & $\begin{array}{c}\text { Jumlah } \\
\text { Responden }\end{array}$ & $\%$ \\
\hline 1. & Tinggi & 13 & 43.33 \\
\hline 2. & Sedang & 10 & 33.33 \\
\hline 3. & Rendah & 7 & 23.33 \\
\hline & Jumlah & $\mathbf{3 0}$ & $\mathbf{1 0 0}$ \\
\hline
\end{tabular}

Tingkat Pemahaman Karyawan terhadap Adipura Berdasar pada Peran Serta

Tingkat pemahaman karyawan terhadap adipura berdasar pada peran serta berbeda-beda. Secara umum tingkat pemahaman karyawan terhadap peran serta dalam kategori tinggi. Rincian tingkat pemahaman karyawan Universitas Lancang Kuning terhadap peran serta seperti pada Tabel 10.

Tabel 10. Tingkat pemahaman karyawan terhadap adipura berdasar pada "Peran Serta"

\begin{tabular}{cccc}
\hline No. & Tingkat Pemahaman & $\begin{array}{c}\text { Jumlah } \\
\text { Responden }\end{array}$ & $\%$ \\
\hline 1. & Tinggi & 25 & 83.33 \\
\hline 2. & Sedang & 3 & 10.00 \\
\hline 3. & Rendah & 2 & 6.67 \\
\hline & Jumlah & $\mathbf{3 0}$ & $\mathbf{1 0 0}$ \\
\hline
\end{tabular}

Berdasar pada Tabel 7 sampai dengan Tabel 10 di atas terlihat bahwa sebagian besar karyawan memiliki tingkat pemahaman terhadap pengertian adipura dalam kategori tinggi. Hal tersebut diduga karyawan sudah cukup berpengalaman dalam hal-hal yang berhubungan dengan kegiatan di lingkungan sekitar. Karyawan fokus pada rutinitas harian dalam menyelesaikan tugas/pekerjaannya, sehingga kurang memperdulikan hal lain yang dianggap kurang penting.
Karyawan telah memiliki pandangan bahwa terdapat beberapa pengaruh adipura terhadap perubahan perilaku, perubahan kebersihan lingkungan, peningkatan fasilitas pengelolaan sampah dan adanya sanksi bagi yang melanggar aturan kebersihan lingkungan. Sebagian besar karyawan telah berkeluarga dan melakukan hubungan sosial dengan masyarakat lainnya untuk berpastisipasi dalam kegiatan-kegiatan kebersihan di lingkungan tempat tinggal mereka. 
KESIMPULAN DAN SARAN

\section{Kesimpulan}

Berdasar pada hasil penelitian dapat disimpulkan sebagai berikut :

1. Tingkat pemahaman mahasiswa Universitas Lancang Kuning terhadap adipura untuk kategori tinggi $(33,33 \%)$, sedang $(56,67 \%)$ dan rendah (10\%).

2. Tingkat pemahaman karyawan Universitas Lancang Kuning terhadap adipura untuk kategori tinggi $(63,33 \%)$ dan sedang $(36,67 \%)$.

\section{Saran}

$$
\text { Perlu dilakukan kegiatan }
$$

sosialisasi tentang manfaat adipura bagi lingkungan dan kehidupan masyarakat untuk menuju kota madani.

\section{DAFTAR PUSTAKA}

Dahlan, EN. 2004. Membangun Kota Kebun Bernuansa Hutan Kota. Bogor : IPB-Press

[Dephut] Departemen Keliutanan. 1997. Panduan Pedoman Survei Sosial Ekonomi Kehutanan Indonesia. Jakarta: Departemen Kehutanan

Koentjaraningrat. 1990. Pengantar IImu Antropologi . Jakarta. Penerbit Rineka Cipta

[PPLH Regional Sumatera] Pusat Pengelolaan Lingkungan Hidup Regional Sumatera. 2007.
Kualitas Lingkungan Hidup Sumatera 2007. Pekanbaru : Pusat Pengelolaan Lingkungan Hidup Regional Sumatera.

Rakhmat, J. 2001. Psikologi Komunikasi. Bandung Penerbit Remaja Rosdakarya]

Rinasari, R. 1998. Hubungan antara Pemahaman Faktor-Faktor Budaya Organisasi dengan Kinerja Pembentukan Pengetahuan (Knowledge Creating ) Karyawan di Kantor Daerah Telekomunikasi Jakarta Selatan. [Tesis]. Jakarta. Universitas Indonesia, Program Pascasarjana Bidang Ilmu Sosial. Program Studi IImu Komunikasi

Soekanto. 5. 2002. Sosiologi Suatu Pengantar. Jakarta Penerbit Raja Grafindo Persada

Walgito, B. 2002. Psikologi Sosial : Suatu Pengantar. Yogyakarta: Penerbit Andi Offset

Winkel, WS. 1 987. Psikologi Pengajaran. Jakarta: Penerbit Gramedia

Zaid, A. 1997. Hubungan Karakteristik Peternak Sapi Perah dengan Sikap dan Perilaku Aktual dalam Pengelolaan Limbah Peternakan. [Tesis]. Bogor. Program Pascasarjana 